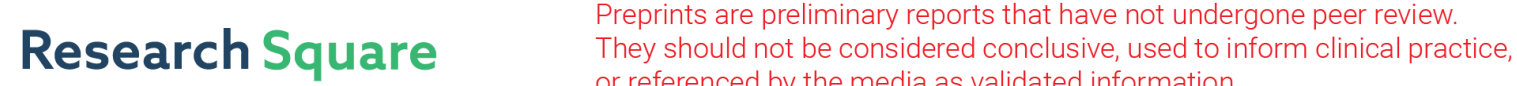 \\ or referenced by the media as validated information. \\ Prediction of Dynamic Elastic Properties for Mishrif formation in West Qurna-1 oil field: an experimental work
}

ahmed wattan ( $\square$ a.watten1308d@coeng.uobaghdad.edu.iq )

university of baghdad

Mohammed AL囚Jawad

University of Baghdad

Article

Keywords: compressional wave velocity, shear wave velocity, sonic

Posted Date: December 29th, 2021

DOI: https://doi.org/10.21203/rs.3.rs-1148988/v1

License: (c) (1) This work is licensed under a Creative Commons Attribution 4.0 International License.

Read Full License 


\title{
Prediction of Dynamic Elastic Properties for Mishrif formation in West Qurna-1 oil field: an experimental work
}

\author{
Abstract \\ Shear and compressional wave velocities are useful for drilling operations, the exploration \\ of reservoirs, stimulation processes, and hydraulic fracturing. \\ An ultrasonic device will be used in this investigation to anticipate and analyze the elastic \\ characteristics of carbonate rocks. At the summit of the field, the well WQ1-20 obtained \\ samples of the Mishrif formation from a variety of various depths.
}

The number of samples taken from the well is nine from different units whereas the number of samples taken from the main unit (MB2) was five.

The relations between the elastic properties for the carbonate rocks with P-and S-waves were defined.

The relations between $\mathrm{Vp}$ and $\mathrm{Vs}$ with elastic properties were defined by applied Regression analysis.

The results showed that a linear relationship between P-and S-wave velocities with the elastic properties of the carbonate rocks.

It is found that the relationship between Vp and Young's modulus (E) is $\mathrm{R}^{2}$ equal to 0.979 while the relationship between Vs and Young's modulus (E) is $\mathrm{R}^{2}$ equal to 0.925 .

The relationship between shear modulus and Vs is good in comparison with Vp where the values of $\mathrm{R}^{2}$ were 0.985 and 0.94 respectively. $\mathrm{R}^{2}$ values for the Bulk modulus and Lame's constant of $\mathrm{Vp}$ are 0.925 and 0.6 , respectively, while the values for Vs are 0.925 and 0.6 for the latter. The relation between $\mathrm{Vp} / \mathrm{Vs}$ ratio with Poisson's ratio showed a good $\mathrm{R}^{2}$ with a value of 0.97 .

When it comes to predicting the dynamic elastic characteristics of a material, the ultrasonic approach may be regarded as a cost-effective, easy, and non-destructive method.

Keywords: compressional wave velocity, shear wave velocity, sonic

\section{Introduction}

The shear and compressional wave velocities (Vs and Vp, respectively) are an insignificant role in the seismic inversion and the evaluation of petrophysical properties, especially for analysis of reservoir geomechanical properties.to find the geomechanical parameters such as shear modulus, Young's modulus, Poisson's ratio, bulk modulus, and Lame parameters, both Vs and Vp with density are needed. Therefore, knowing Vs, Vp, and density, other 
elastic parameters of a rock formation can be calculated in terms of the acoustic wave velocities (Liu et al. 2012). [1]

Ultrasonic wave velocity tests are sought after in rock mechanics because they are considered non-destructive to core plugs, simple to apply, and inexpensive. [2]

The methods to find the sonic velocity are frequency resonant techniques the ultrasonic and low-frequency sonic waves $[3,4]$.

The ultrasonic approach, which is considered the most convenient, may be used to figure out the mechanics of rocks using one of these ways.

The method of ultrasonic wave velocity is useful to find the S-and P-wave velocities and the constants of ultrasonic that are useful in defining the dynamic properties for the core plugs such as shear modulus, Young's modulus, Poisson's ratio, and bulk modulus. This method can be used in both laboratory and field because it is easy to use the device ultrasonic and fast. $[\mathbf{5 , 6}]$

Numerous researches employed ultrasonic techniques to separate the various geomaterials and found that this was the best approach to analyze the elastic characteristics of these materials. [7, 8-11]

P- and S-wave velocities were shown to be closely related to a wide variety of rock parameters. [2, 3, 12- 17]

Seismic velocity is strongly correlated with rock characteristics, according to the findings.

Seismic velocity and rock characteristics seem to be tightly linked, according to the findings. Analyzing dynamic elastic characteristics of carbonate rocks in Mishrif reservoir by employing an ultrasonic technique and a low-cost way to establish the association between $\mathrm{P}$ and $\mathrm{S}$ wave velocities and rock properties is what the research is all about

\section{Location of the Study Area}

West Qurna is a supergiant oil field in the southeast of Iraq; it is around 70 kilometers north-west of Basra. The field is located between $\left(3425.000^{\circ}-3400.000^{\circ}\right)$ north longitudes and $\left(716000^{\circ}-732000^{\circ}\right)$ east latitudes. As shown in Figure 1. 


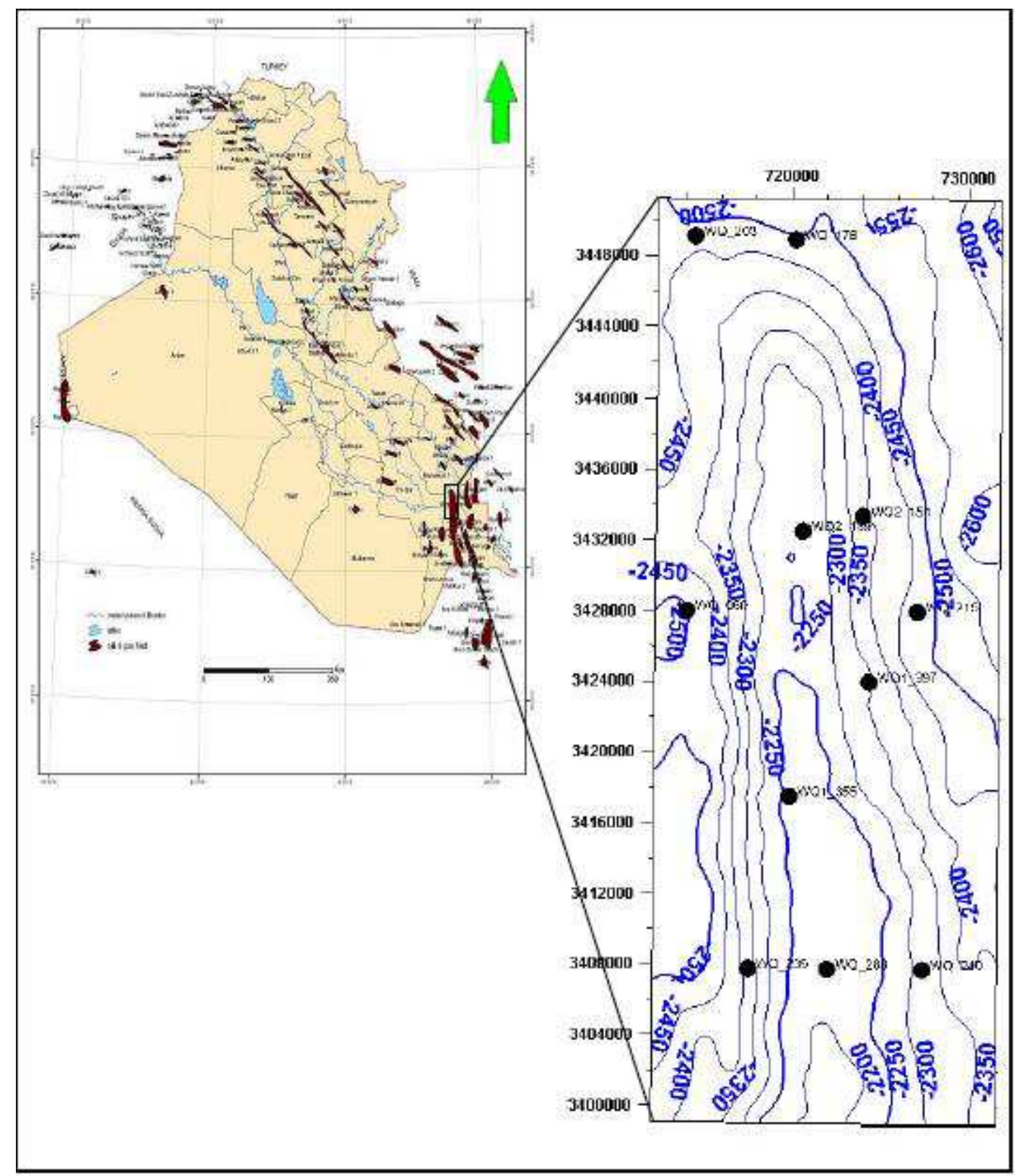

Figure 1: Location Map of West Qurna-1 Oilfield Southern of Iraq

\section{Geology of the Study Area}

A heterogeneous carbonate reservoir has formed in the West Qurna-1 oil field, known as Mishrif.

An important reservoir not just in the West Qurna-1 area but across southern Iraq is the Mishrif formation. Above and below, as seen in Figure 2, the Khasib Formation and Rumaila Formation separate this formation.

Mishrif formation consists of the anticlinal fold with gentle dips. The length of the structure is about $42 \mathrm{~km}$ and width $16.5 \mathrm{~km}$ from the center of the area, and the depth of Mishrif 
formation at top of the structure is (2207 m) at well (WQ-110), and thickness about (202 $\mathrm{m})$.

CapRock I, Upper Mishrif (MA), Cap Rock II, and Lower Mishrif (LM) are all Mishrif Formation units in the West Qurna oil field (MB1 and MB2 respectively).

\section{1-Cap Rock I}

CapRock I is the upper part of the Mishrif formation. It consists of compact limestone, mudstone, and wackestone. It is locally clayey, particularly in the higher section. This unit is characterized by relatively low porosity and permeability.

\section{2-MA unit (Upper Mishrif)}

MA or upper Mishrif unit starts with the porous limestone below the tight Cap Rock I and the bottom of this unit is the top of the compact limestone of Cap Rock II. The highest section of this unit is limestone, followed lower by limestone with some packstone and lastly limestone. Fine-grained chalky textured limestone dominates the majority of this unit.

\section{3-Cap Rock II}

This unit comprises limestone developed in a sub-tidal environment, hard, thick, nonfossiliferous, and sometimes shaly. Because of its compactness and lack of porosity, this unit serves as a cap rock for unit MB1.

\section{4-MB1 unit (Lower Mishrif)}

This unit starts with the porous limestone below the tight Cap Rock II. This unit is an important portion of the Mishrif Formation since it holds a significant amount of Mishrif oil. This is because it includes the porous and permeable Rudists biostromes.

\section{5-MB2 unit (Lower Mishrif)}

Because of its high porosity and permeability, this unit is highly regarded. The Rumaila formation's sub-basinal facies lies at the base of this unit, which descends from MB1's lowest biostrome. 


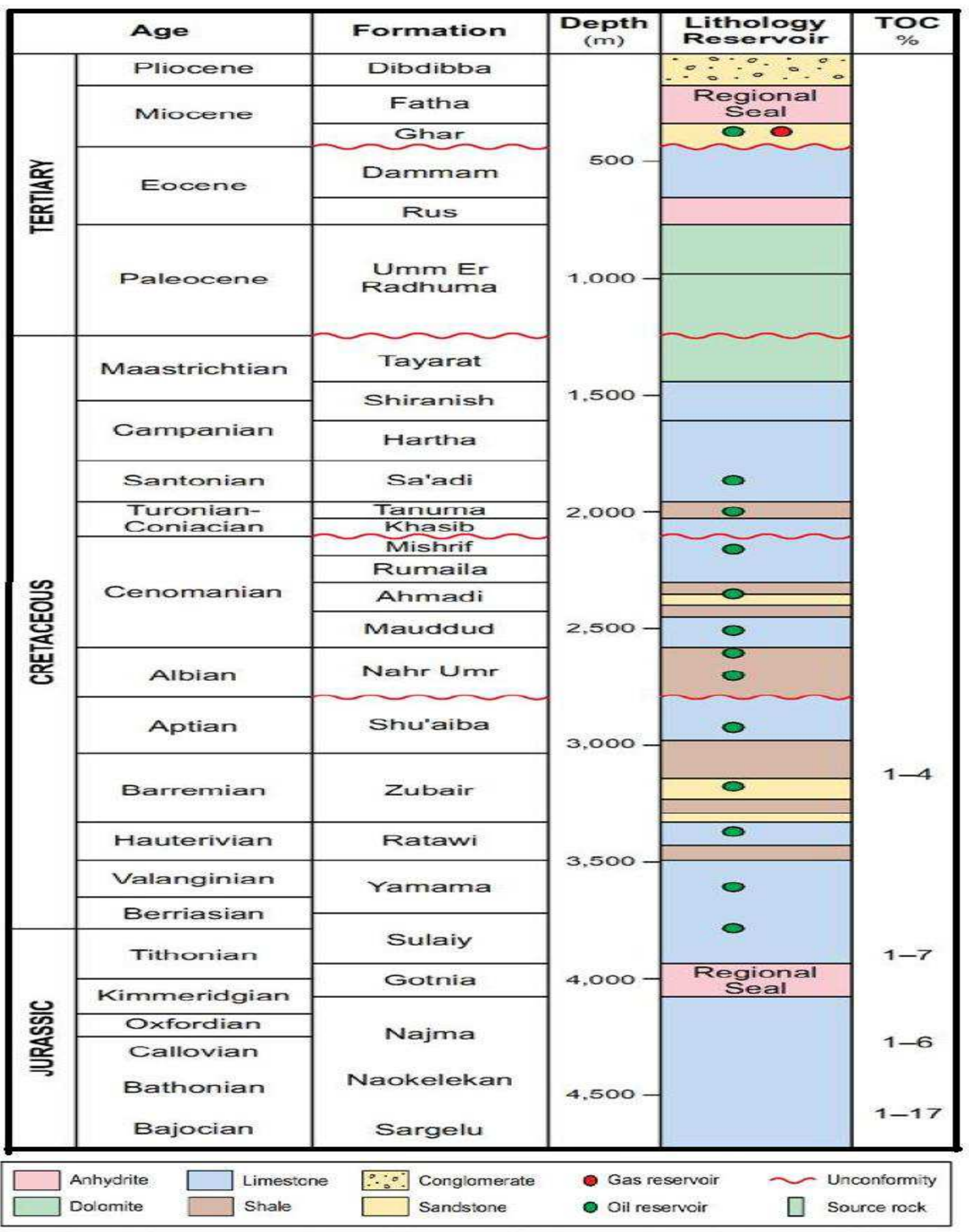

Figure 2: Stratigraphic column for the southern region of Iraq.

\section{Collection and processing of samples}


Eleven rock samples were taken from the well WQ1-20 for Mishrif formation. The vertical intervals between the core plugs were not equal. The length of cores was a range between $6.8 \mathrm{~cm}$ in core number two and $7.22 \mathrm{~cm}$ for core number 7 . the plugs one and eight were damaged. The depth of Mishrif formation for each core is illustrated in table 1.

Table 1: The collected samples from WQ1-20

\begin{tabular}{|c|c|c|c|c|}
\hline WQ & 20 & & & \\
\hline diameter & $\mathbf{3 . 7 4 5} \mathbf{~ c m}$ & & & \\
\hline Plug no & depth & unit & Length (cm) & Core description \\
\hline 1 & 2246.86 & MA-1 & 7 & Ls, bu, hd, styl, p p vug \\
\hline 2 & 2256.39 & MA-2 & 6.8 & Ls, bu, hd, f p p vug \\
\hline 3 & 2273.33 & MB-1 & 7.14 & Ls, bu, hd, styl, grad-cont \\
\hline 4 & 2279.73 & MB-1 & 7.7 & Ls, bu, hd, chky, p p vug \\
\hline 5 & 2310.78 & MB-2 & 7 & Ls, bu, hd, chky, p p vug, \\
\hline 6 & 2315.64 & MB-2-1 & 7.05 & Ls, bu, hd, chky, p p vug \\
\hline 7 & 2320.44 & MB-2-1 & 7.22 & Ls, bu, hd, chky, p p vug \\
\hline 8 & 2325.5 & MB-2-2 & 7 & Ls, bu, hd, chky, p p vug \\
\hline 9 & 2330.5 & MB-2-2 & 7.1 & Ls, bu, hd, chky, micro-frac \\
\hline 10 & 2320.62 & MB-2-1 & 7.07 & Ls, bu, hd, chky, p p vug \\
\hline 11 & 2321.86 & MB-2-1 & 7.2 & Ls, bu, hd, dead oil, chky \\
\hline
\end{tabular}

\section{Density measurements}

$$
\rho\left(\mathrm{kg} / \mathrm{m}^{3}\right)=\frac{\text { mass of sample }}{\text { volume of sample }}
$$

Because of the compaction and microfractures, the density for the dry core plugs ranged from $1918 \mathrm{~kg} / \mathrm{m} 3$ to $2253 \mathrm{~kg} / \mathrm{m} 3$.

\section{The calculations of velocity}

The New Sonic Viewer (model 5217A) at the petroleum engineering lab at the University of Baghdad was used to determine the shear and compressional wave velocities for the core samples. Transmitted ultrasonic impulses are captured in the transit time ( $t$ ). The transducers were pushed to the ends of the core samples using the core plugs, which were 
then put between the transmitter and receiver until a steady transit time could be recorded. To get good contact between the transducers and the surface of samples we put special grease between them.

To calculate the shear and compressional wave velocities (Vs and Vp ) values the following equations will be used :

$V p=\frac{L}{T p} \ldots \ldots \ldots \ldots \ldots \ldots \ldots \ldots \ldots \ldots \ldots \ldots \ldots \ldots$

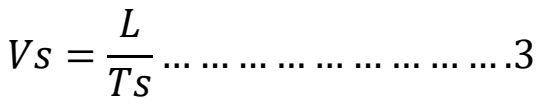

Where:

$\mathrm{L}=$ the sample length in $\mathrm{cm}$

$\mathrm{Tp}$ and $\mathrm{Ts}=$ the transit time ( $\mathrm{P}$ and $\mathrm{S}$ wave $)$

The compressional velocity (Vp) values of samples at the study area varied from 2073.17 $\mathrm{m} / \mathrm{s}$ to $4353.65 \mathrm{~m} / \mathrm{s}$ with an average value of $2796.74 \mathrm{~m} / \mathrm{s}$, while the shear velocity (Vs) values varied from $1546.05 \mathrm{~m} / \mathrm{s}$ to $2789.06 \mathrm{~m} / \mathrm{s}$ with an average value of $1840.59 \mathrm{~m} / \mathrm{s}$.

The waveform for plug no 10 as in the following figure

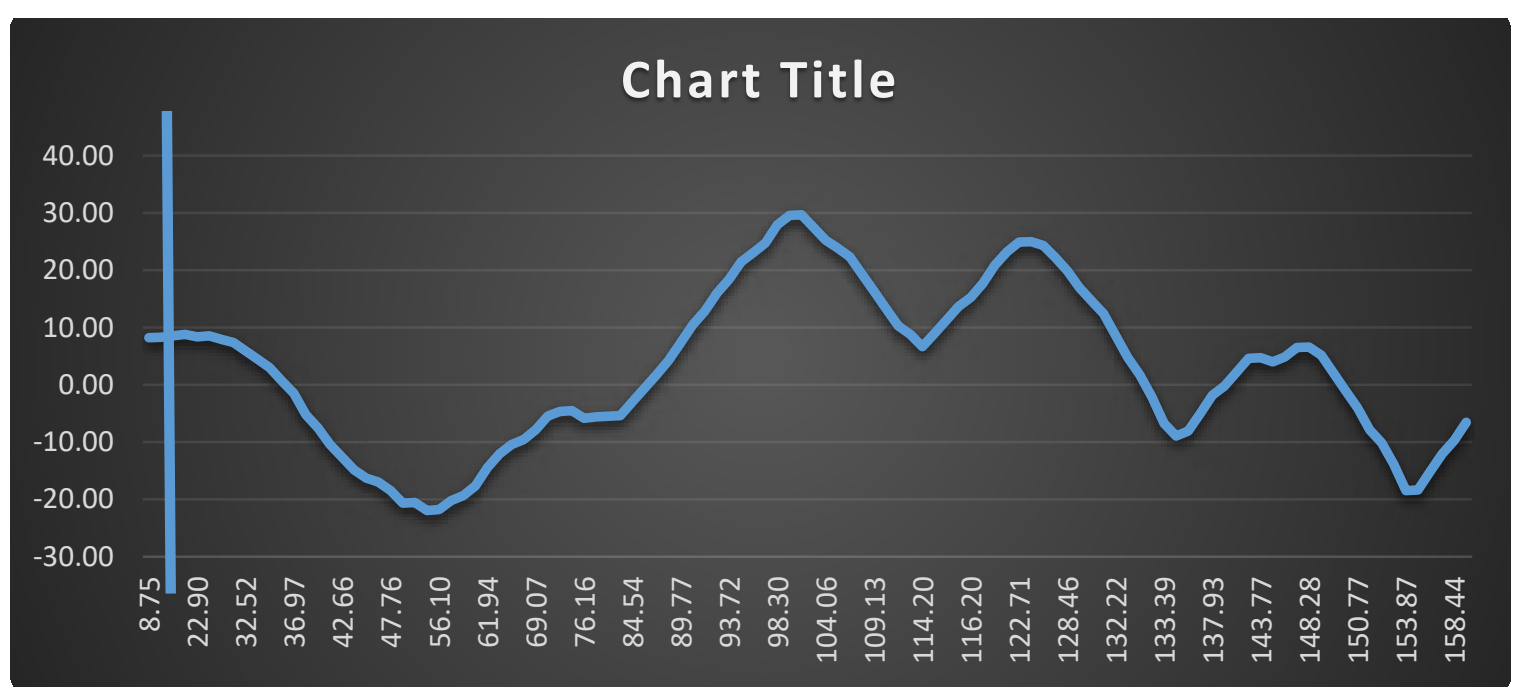

Figure 3: P wave velocity form for plug no 10

\section{Dynamic elastic moduli}

Shear modulus, Young's modulus, bulk modulus, Poisson's ratio, and the Lame's constant are all examples of elastic moduli. [20]. 
The following formulae may be used to determine the elastic moduli of core plugs by measuring their compressional and shear wave velocities and densities:

$$
\begin{gathered}
E=\frac{\rho v_{S}^{2}\left(3 v_{P}^{2}-4 v_{S}^{2}\right)}{v_{P}^{2}-v_{S}^{2}}, \\
K=\rho\left(v_{P}^{2}-4 / 3 v_{S}^{2}\right) \\
\sigma=\frac{v_{P}^{2}-2 v_{S}^{2}}{2\left(v_{P}^{2}-v_{S}^{2}\right)} \\
G=\rho v_{S}^{2} \\
\lambda=\rho\left(V_{P}^{2}-2 V_{S}^{2}\right)
\end{gathered}
$$

Where the bulk modulus K, the Poisson's ratio, the shear modulus G, the Lame's constant, the density, the velocity of the P-wave and the velocity of the S-wave, and Young's modulus E are all included.

\section{The Results and discussion}

The properties found from compressional and shear wave velocities for the core plugs collected from the well WQ1-20 are mentioned in table 2 where the values for the elastic properties for the core samples are different.

The values of young modules $(\mathrm{E})$ ranged from $1.0716 \mathrm{E}+10$ to $3.73 \mathrm{E}+10$, the bulk modulus $(\mathrm{K})$ ranged from $0.4272 \mathrm{E}+10$ to $1.78 \mathrm{E}+10$, the poisons ratio $(\sigma)$ ranged from 0.037 to 0.25 .

The shear modulus $(\mathrm{G})$ ranged from $0.472 \mathrm{E}+10$ to $1.62 \mathrm{E}+10$, and the Lame's constant $(\lambda)$ ranged from $0.046 \mathrm{E}+10$ to $0.84 \mathrm{E}+10$ Pascal.

To describe the relationship between the elastic modulus and the ultrasonic wave velocities for the core plugs, applying regression analysis .taking the best equation that gives the best fit line and the high value of $\mathrm{R}^{2}$ for each equation. This section aims to present and discuss the correlations found from the velocity measurements to estimate the properties of core plugs. 
Table 2: For the core samples studied in this location, the velocity measurements yielded the most important attributes.

\begin{tabular}{|c|c|c|c|c|c|c|c|c|c|}
\hline $\begin{array}{c}\text { plug } \\
\text { no }\end{array}$ & $V p(m / s e c)$ & $\mathrm{Vs}(\mathrm{m} / \mathrm{sec})$ & VB & E & $\mathbf{K}$ & VP/VS & $\sigma$ & G & $\boldsymbol{\lambda}$ \\
\hline 4 & 2490.385 & 1726.667 & 85.6228 & 1.18639 & 0.4272 & 1.44231 & 0.0371 & 0.57195 & 0.0459 \\
\hline 6 & 2381.757 & 1546.053 & 77.6886 & 1.0716 & 0.49053 & 1.54054 & 0.1359 & 0.4717 & 0.17607 \\
\hline 7 & 2776.923 & 1961.957 & 79.562 & 1.54541 & 0.51684 & 1.41538 & 0.0017 & 0.77143 & 0.00256 \\
\hline 5 & 2536.232 & 520.37 & 77.1376 & 1.36672 & 0.66054 & 1.56522 & 0.1551 & 0.59158 & 0.26615 \\
\hline 11 & 2571.429 & 1550.722 & 79.3416 & 1.12812 & 0.65795 & 1.65821 & 0.2142 & 0.46454 & 0.34825 \\
\hline 10 & 2638.06 & 1822.165 & 77.909 & 1.37492 & 0.50231 & 1.44776 & 0.0438 & 0.65861 & 0.06323 \\
\hline 2 & 2428.571 & 1619.048 & 74.9337 & 1.18341 & 0.49309 & 1.5 & 0.1 & 0.53791 & 0.13448 \\
\hline 3 & 4353.659 & 2789.063 & 78.6804 & 3.73563 & 1.78892 & 1.56098 & 0.152 & 1.62141 & 0.70798 \\
\hline 9 & 3349.057 & 1929.348 & 78.2396 & 2.07634 & 1.39335 & 1.73585 & 0.2516 & 0.82945 & 0.84038 \\
\hline
\end{tabular}

\section{The relationship between $\mathrm{Vs}$ and $\mathrm{Vp}$}

The relationship between $\mathrm{Vp}$ and $\mathrm{Vs}$ is established from the values taken from the ultrasonic device. The relationship was positive linear between $\mathrm{Vp}$ and $\mathrm{Vs}$ with the coefficient of determination $\mathrm{R}^{2}$ equal to 0.8768 as shown in Figure- 4 . The equation for the relationship between ( $\mathrm{Vp}$ and $\mathrm{Vs}$ ) is given below:

$\mathrm{Vs}=0.5368 \mathrm{Vp}+339.22$

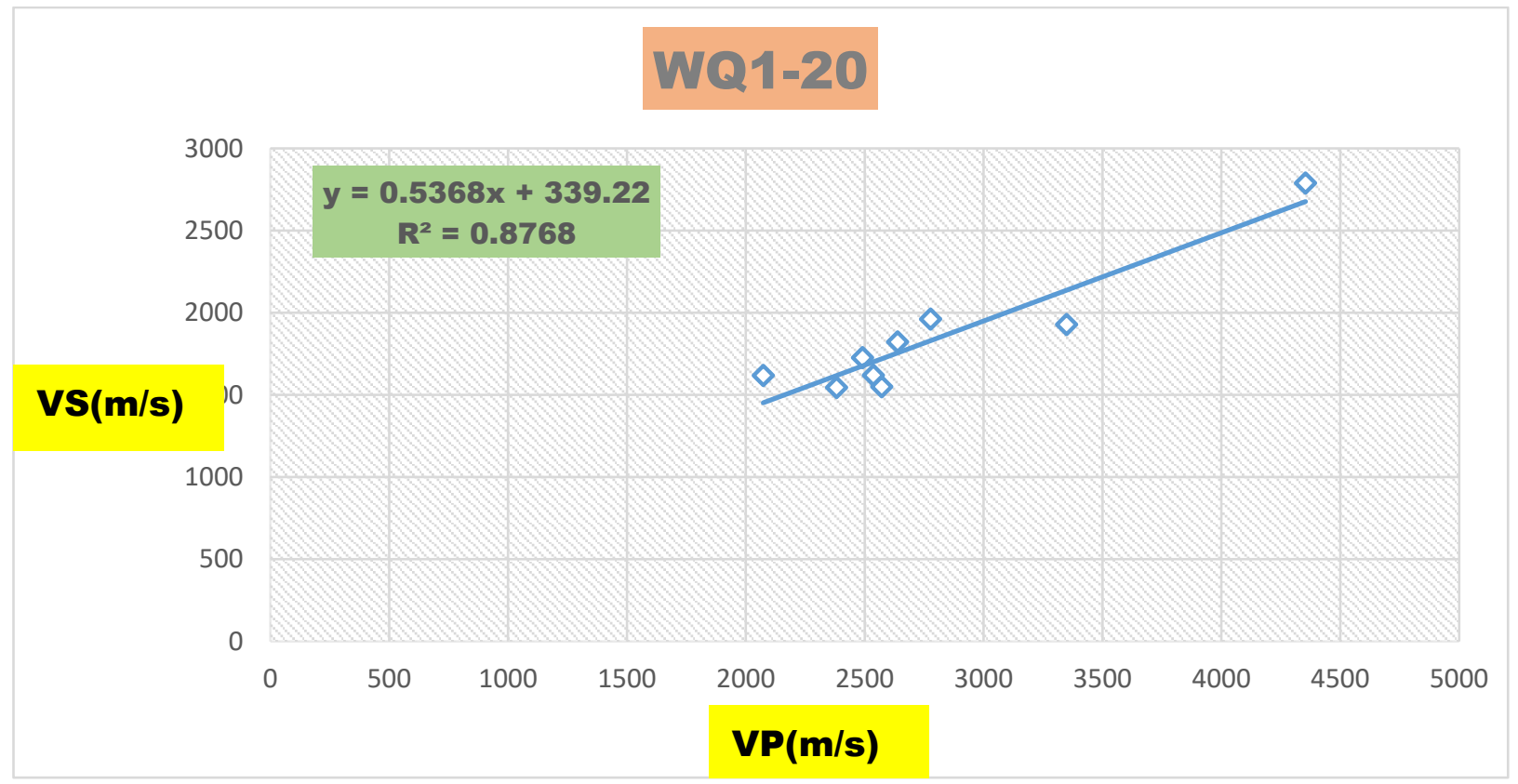

Figure 4: The relationship between Vp and Vs values of Mishrif Formation 


\section{The relationship between rock density $(\rho)$ and $P$-and $S$-wave velocities}

Figures $(5,6)$ show the connection between rock density $(\rho)$ and $(\mathrm{Vp}$ - and $\mathrm{Vs})$ for the rock samples. The P- and S-wave velocities rose linearly as the rock density $(\rho)$ increased. In the following table, the empirical relationships between $(\rho)$ and $\mathrm{Vp}$ and $\mathrm{Vs}$ are shown.

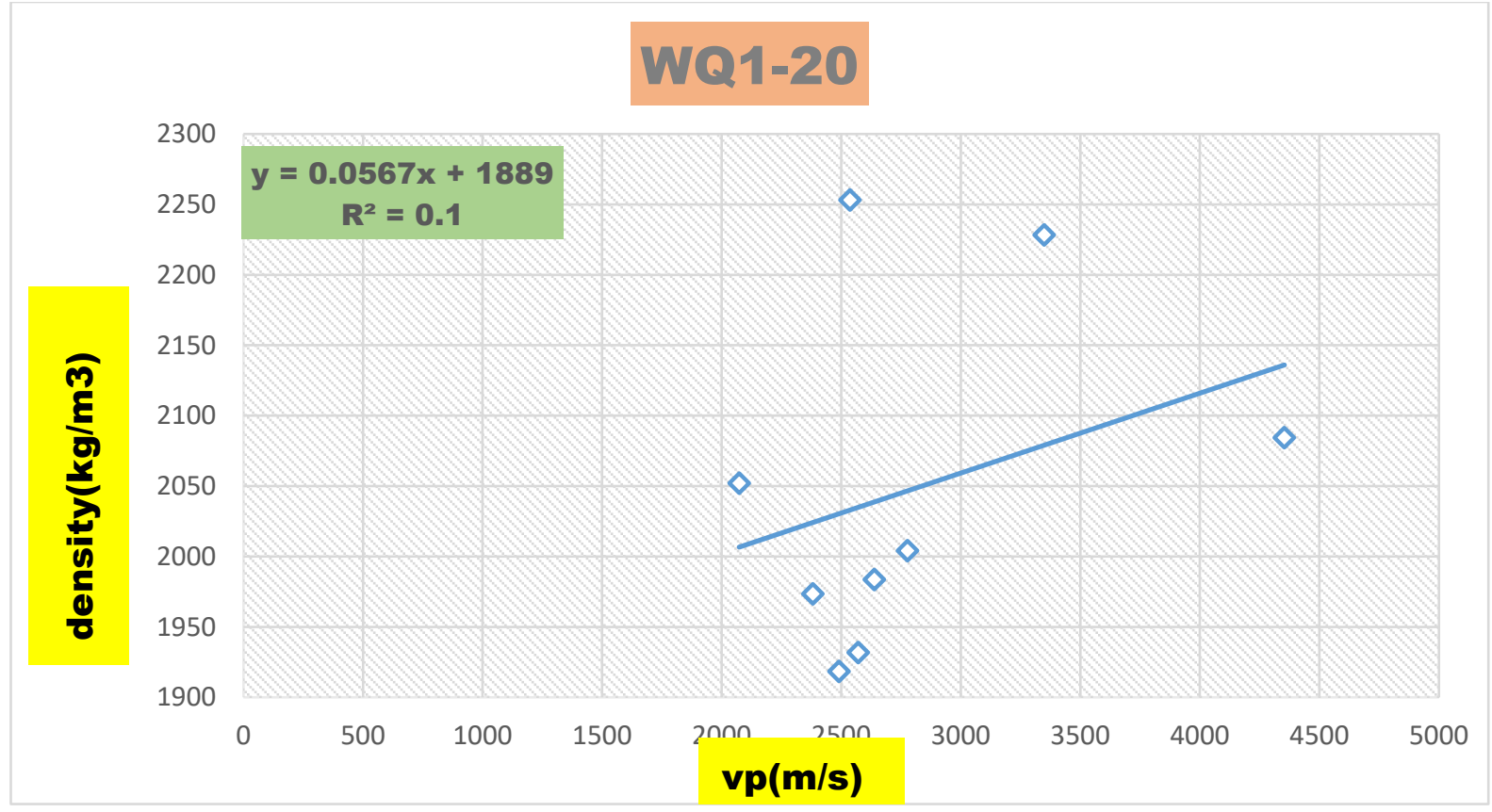

Figure 5:The relation between $\mathrm{Vp}$ and $\rho$ of mishrif formation

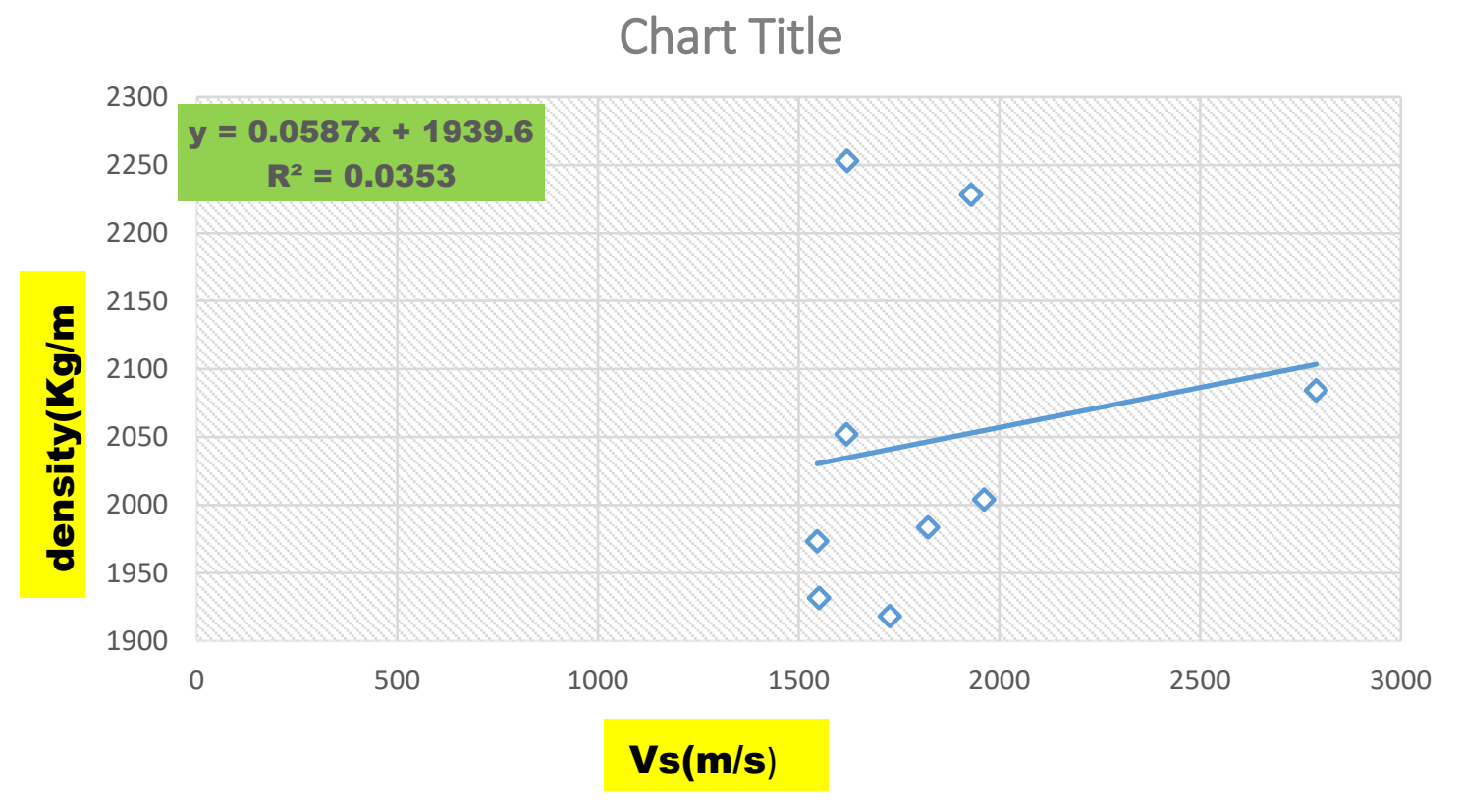

Figure 6:The relation between $\mathrm{Vp}$ and $\rho$ of mishrif formation 


\section{The relationship between Young's modulus (E) and P-and S-wave velocities}

An elastic modulus is a measure of a material's ability to withstand deformation under stress. The Young's modulus of compacted cemented rocks is greater than that of porous rocks. Young's modulus is an indicator of how much stress is necessary to distort a material.

Figures- 7 and 8 show a linear relationship with high regression coefficient values $\left(\mathrm{R}^{2}=0.97\right.$ and 0.92) between $\mathrm{E}$ and (P- and $\mathrm{S}$ ) wave velocities, respectively. The empirical relations between $\mathrm{E}$ and $\mathrm{Vp}$ and $\mathrm{Vs}$ are given below:

$$
\begin{aligned}
& \mathrm{E}=0.0013 * \mathrm{Vp}-2.0323 \\
& \mathrm{E}=0.0022 * \mathrm{Vs}-2.4514
\end{aligned}
$$

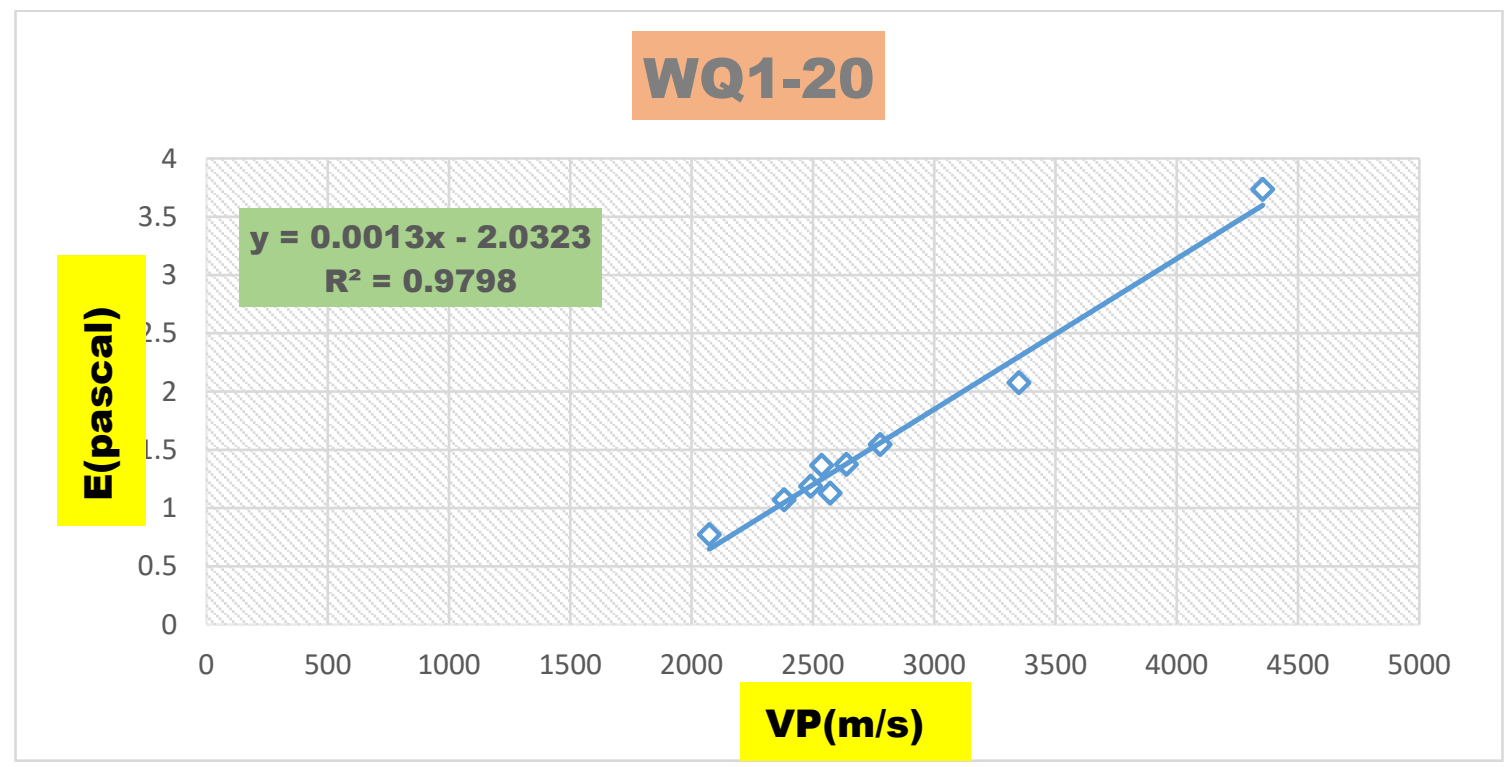

Figure 7-The relation between $\mathrm{Vp}$ and (E) of mishrif formation 


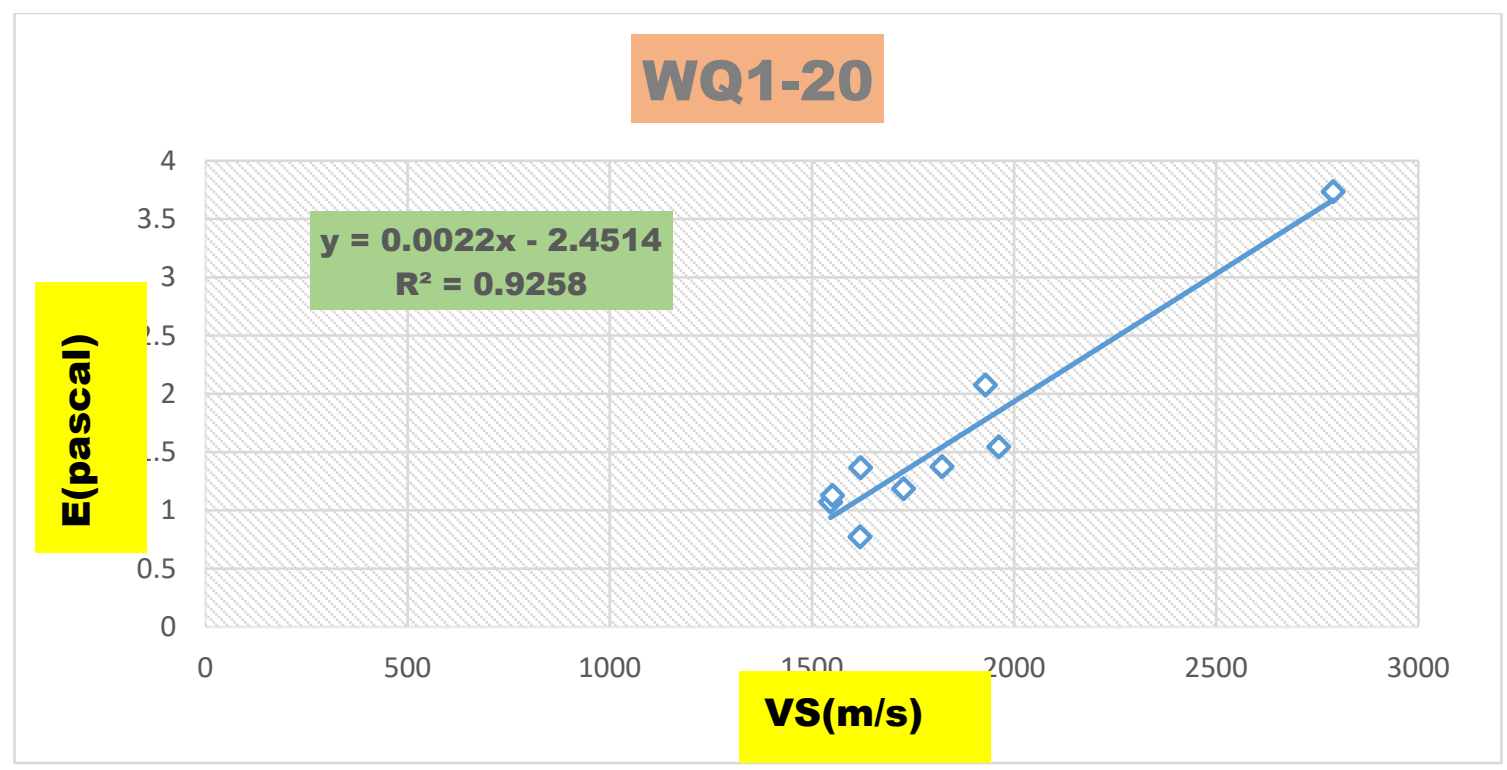

Figure 8: The relation between Vs and (E) of mishrif formation

\section{Correlation between (K) and (Vp and Vs)}

Bulk modulus is another elastic constant that has been investigated in this study. These rocks are being tested for their ability to withstand compression. Compared to porous rocks, compacted cemented rocks have a higher K content. Figures- 9 and 10 show the relationship between $\mathrm{K}$ and ( $\mathrm{P}$ - and $\mathrm{S}$-wave) velocities. There is a strong linear positive connection between the $\mathrm{K}$ and $\mathrm{Vp}$, whereas there is a weak linear positive correlation between the $\mathrm{K}$ and Vs, according to the high regression coefficient $\left(\mathrm{R}^{2}=0.92\right)$. These relationships are shown in the following equation:

$\mathrm{K}=0.0007 * \mathrm{Vp}-1.321$

$\mathrm{K}=0.5789 * \mathrm{Vp}+198.78$ 


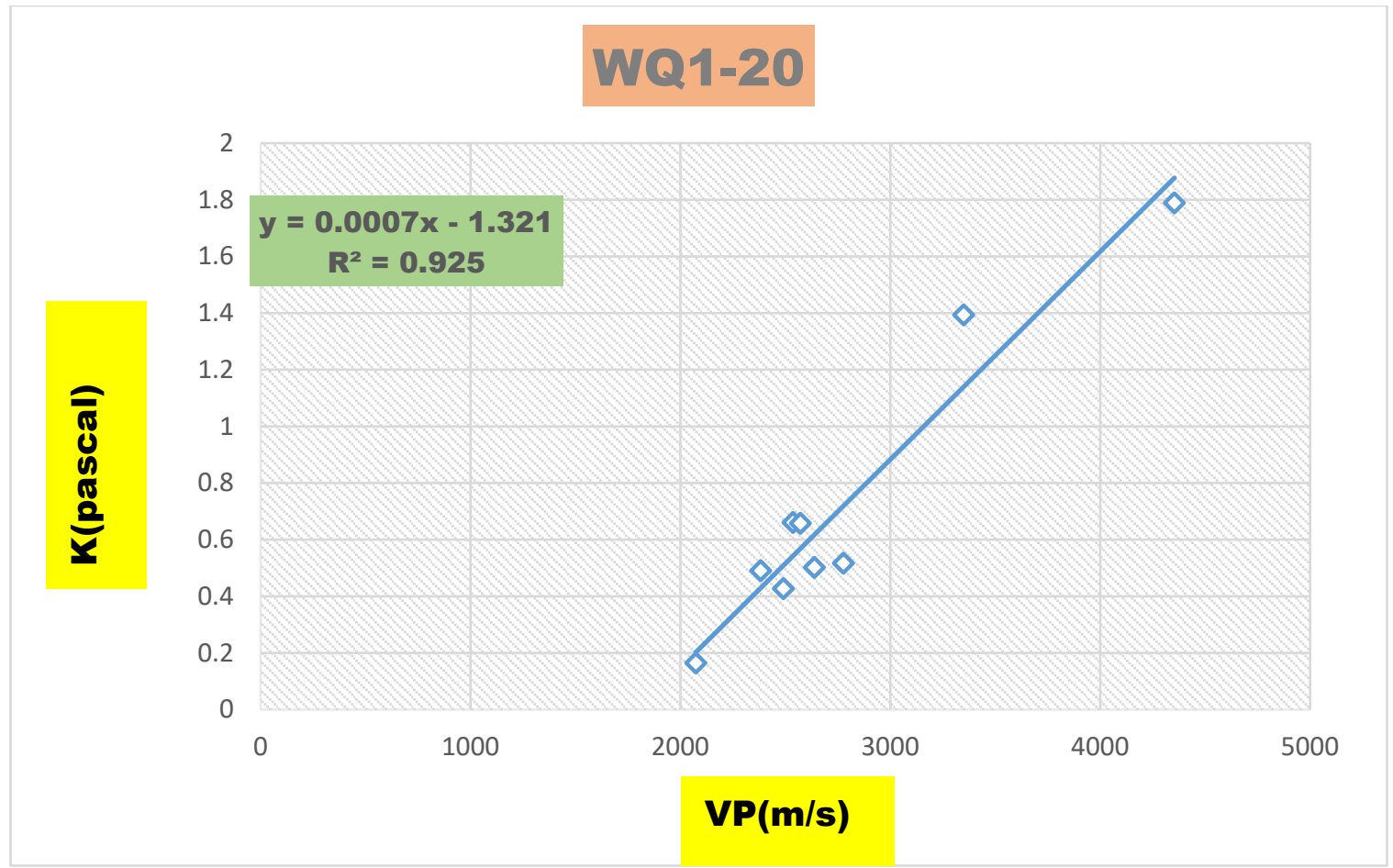

Figure 9: The relation between $\mathrm{Vp}$ and $(\mathrm{K})$ in the study area.

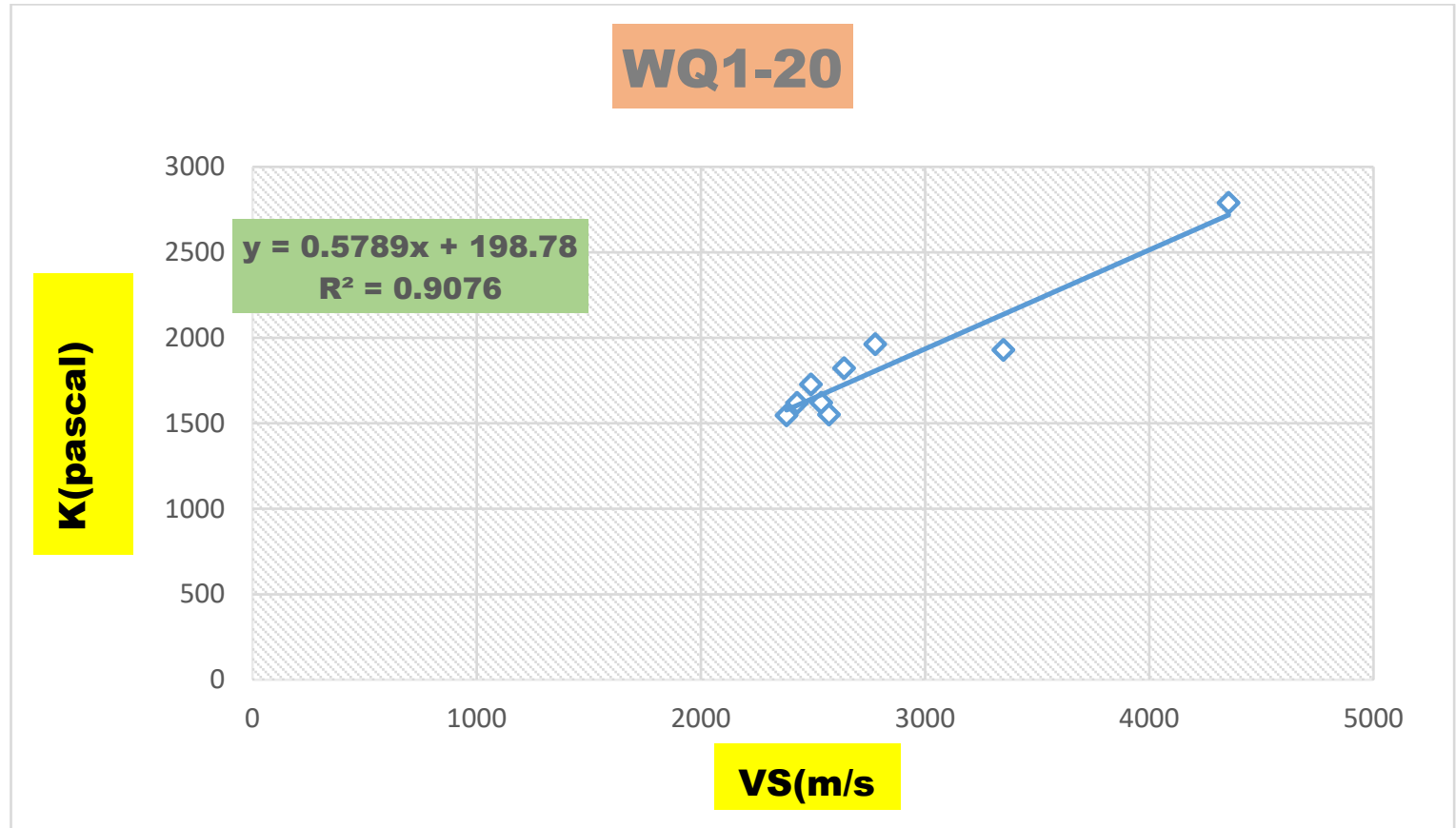

Figure 10: The relation between $\mathrm{Vs}$ and $(K)$ in the study area. 


\section{Correlation between $(\sigma)$ and velocity Ratio (Vp/Vs)}

Engineering studies rely heavily on the Velocity Ratio (Vp/Vs), which is a stronger predictor of lithology than individual velocity values, and Poisson's ratio $(\sigma)$, which is a better indicator of rock quality and strength (Vp and Vs ) .[21,22]

The relationship between $\mathrm{Vp} / \mathrm{Vs}$ and $(\sigma)$ is plotted in Figure-11. It shows a linear relationship with high a regression coefficient $\left(\mathrm{R}^{2}=0.9677\right)$, which indicates that the Poisson's ratio increases linearly with increasing $(\mathrm{Vp} / \mathrm{Vs})$. The following equation defines this relationship:

\section{$\sigma=0.78606(\mathrm{Vp} / \mathrm{Vs})-1.0814$}

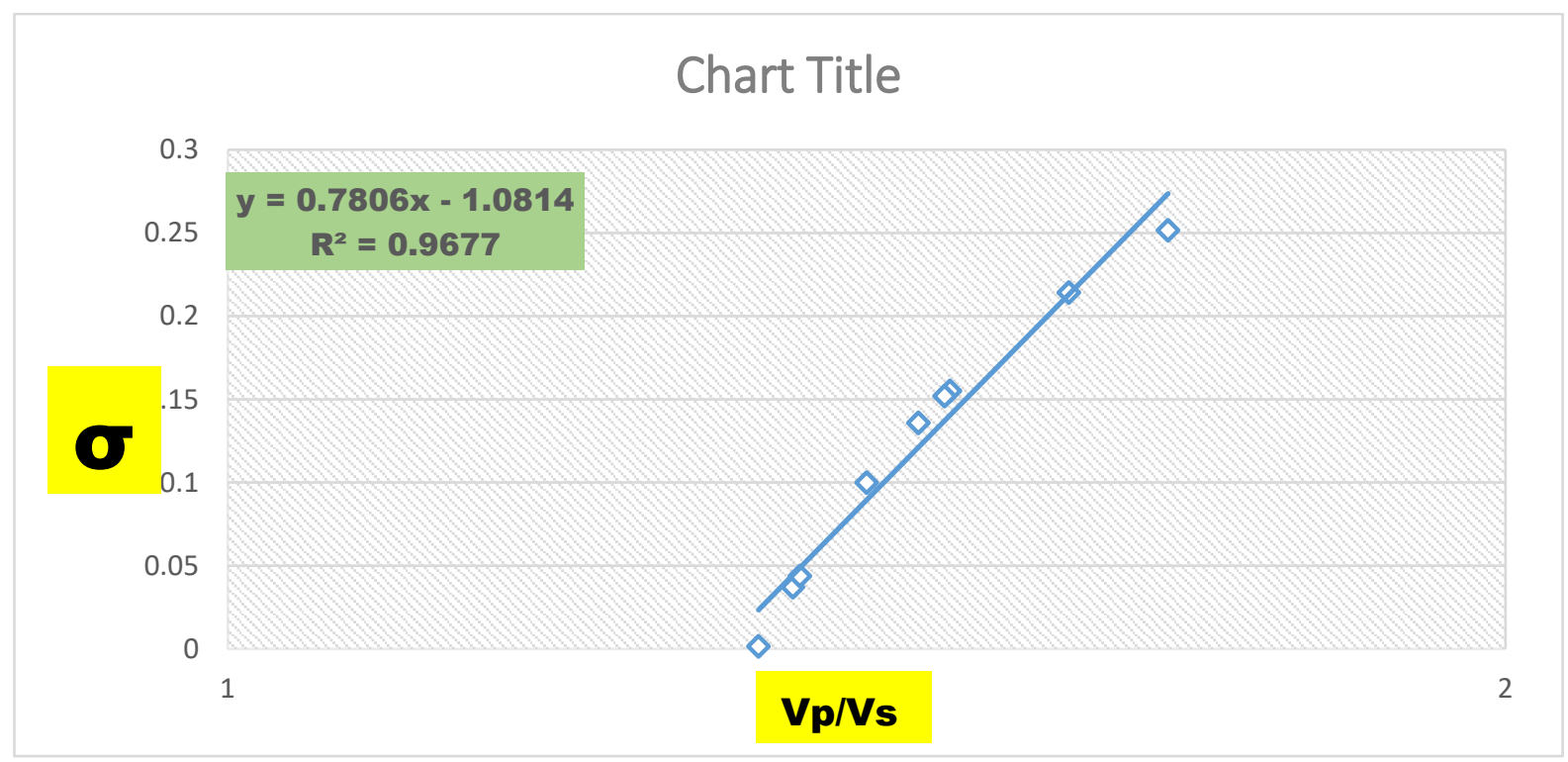

Figure 11: The relation between $(\mathrm{Vp} / \mathrm{Vs})$ and $(\sigma)$ in the study area.

\section{The relationship between shear modulus (G) and (Vp and Vs)}

The shear modulus is defined as the ratio of shear stress to shear strain. It is also known as the modulus of rigidity and may be denoted by G.

Shear modulus can be used to examine the rigidity of the rock. [20]

The shear modulus of hard rocks is greater than that of soft rocks. It takes more stress to create deformation in rocks with a higher shear modulus value. The relationship between compressional wave velocity and the shear modulus with a regression coefficient that is equal to 0.94 as in figure- 12 .

A similar relationship between shear wave velocity and shear modulus with a higher determination coefficient $\mathrm{R}^{2}$ that is equal to 0.98 as in figure- 13 . 


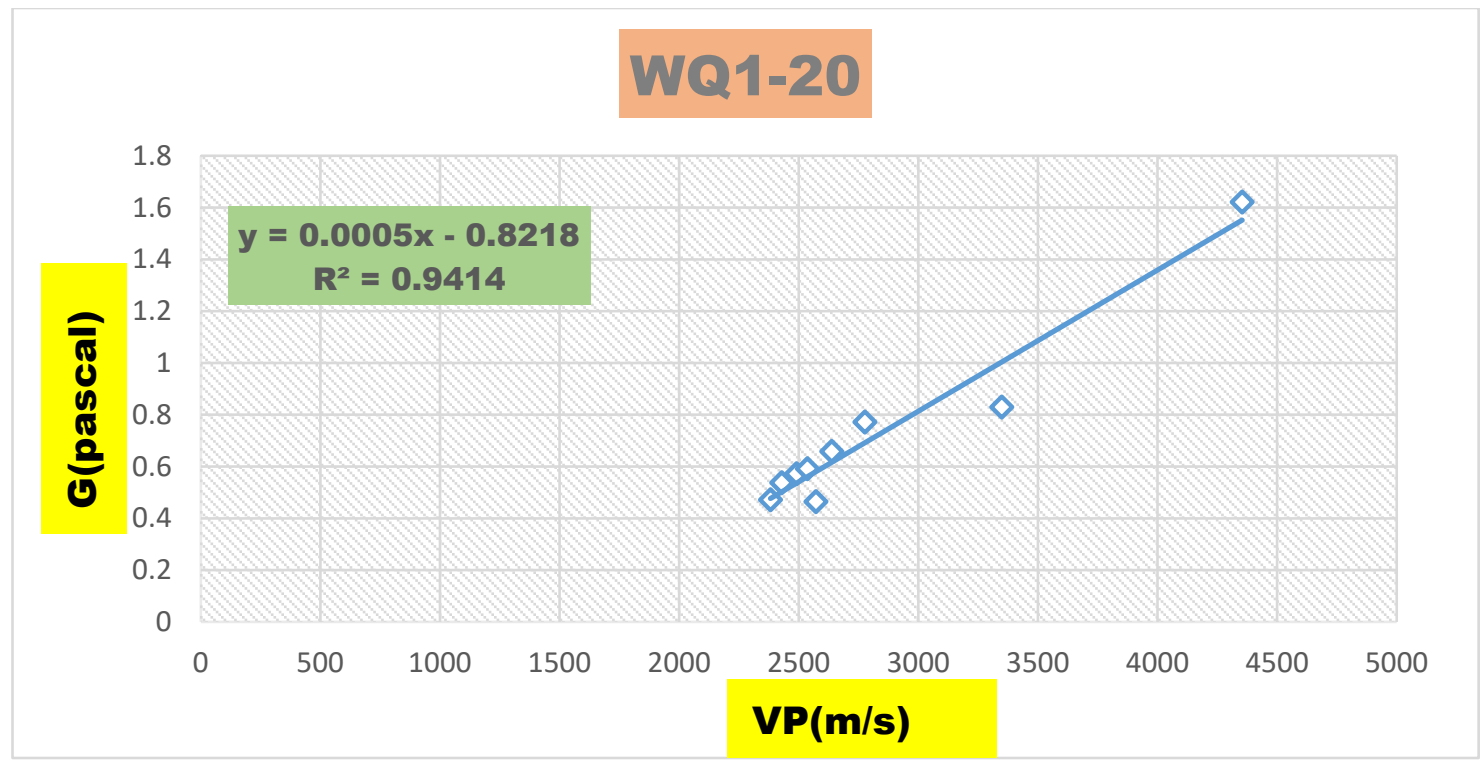

Figure 12-The relationship between Vp and $G$ for the core plugs
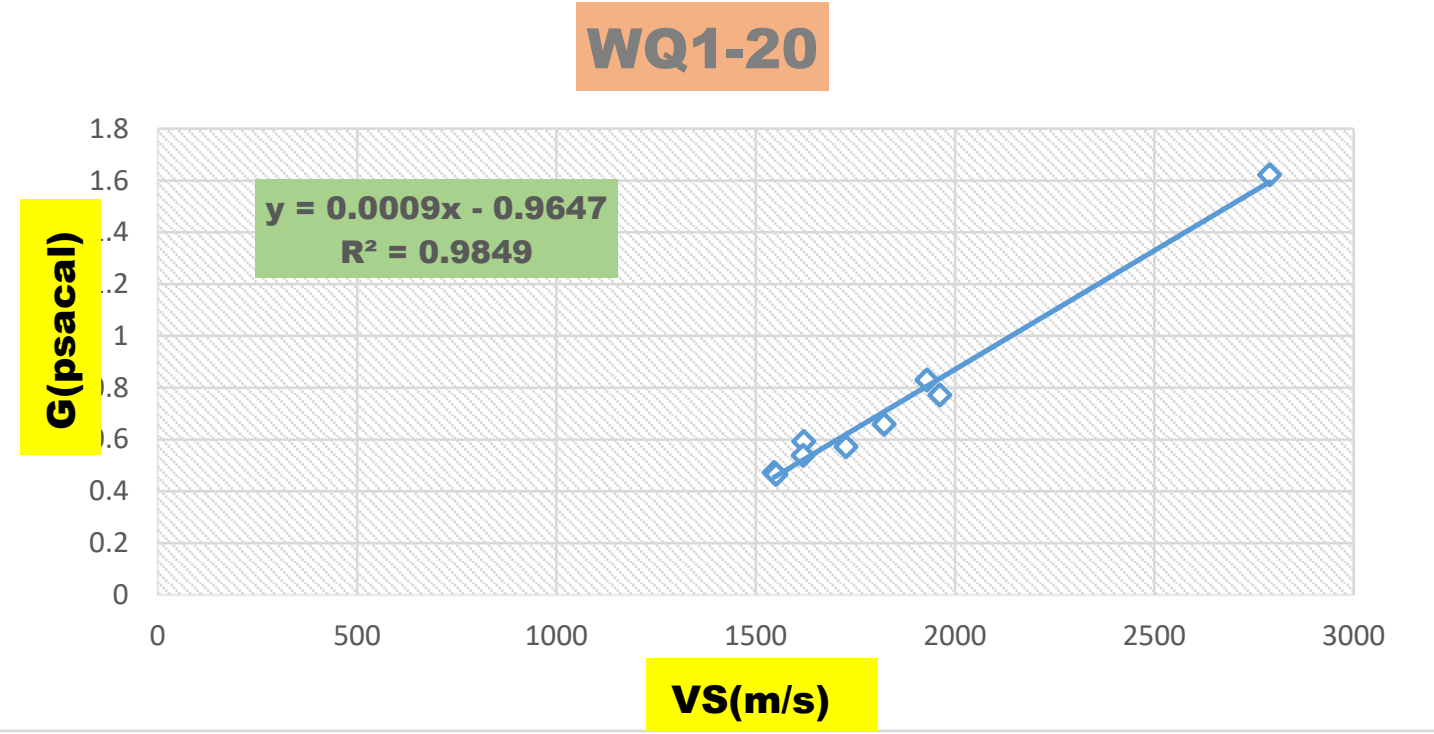

Figure 13-The relationship between Vs and $G$ for the core plugs

The relationship between $(\lambda)$ and (Vp and Vs)

Core plug seismic velocities ( $\mathrm{Vp}$ and $\mathrm{Vs}$ ) and the Lames constant are depicted in figures 14 and 15. The linear connection between Vs and Vp with Lame's constant and high-value regression coefficient $R^{2}$ means that the grows linearly with rising $\mathrm{Vp}$. Here are the empirical correlations between $\lambda$ and $\mathrm{Vp}$ and Vs:

$$
\begin{gathered}
\lambda=0.0004 * V p-0.7303 \\
\lambda=0.0004 * V s-0.4753
\end{gathered}
$$




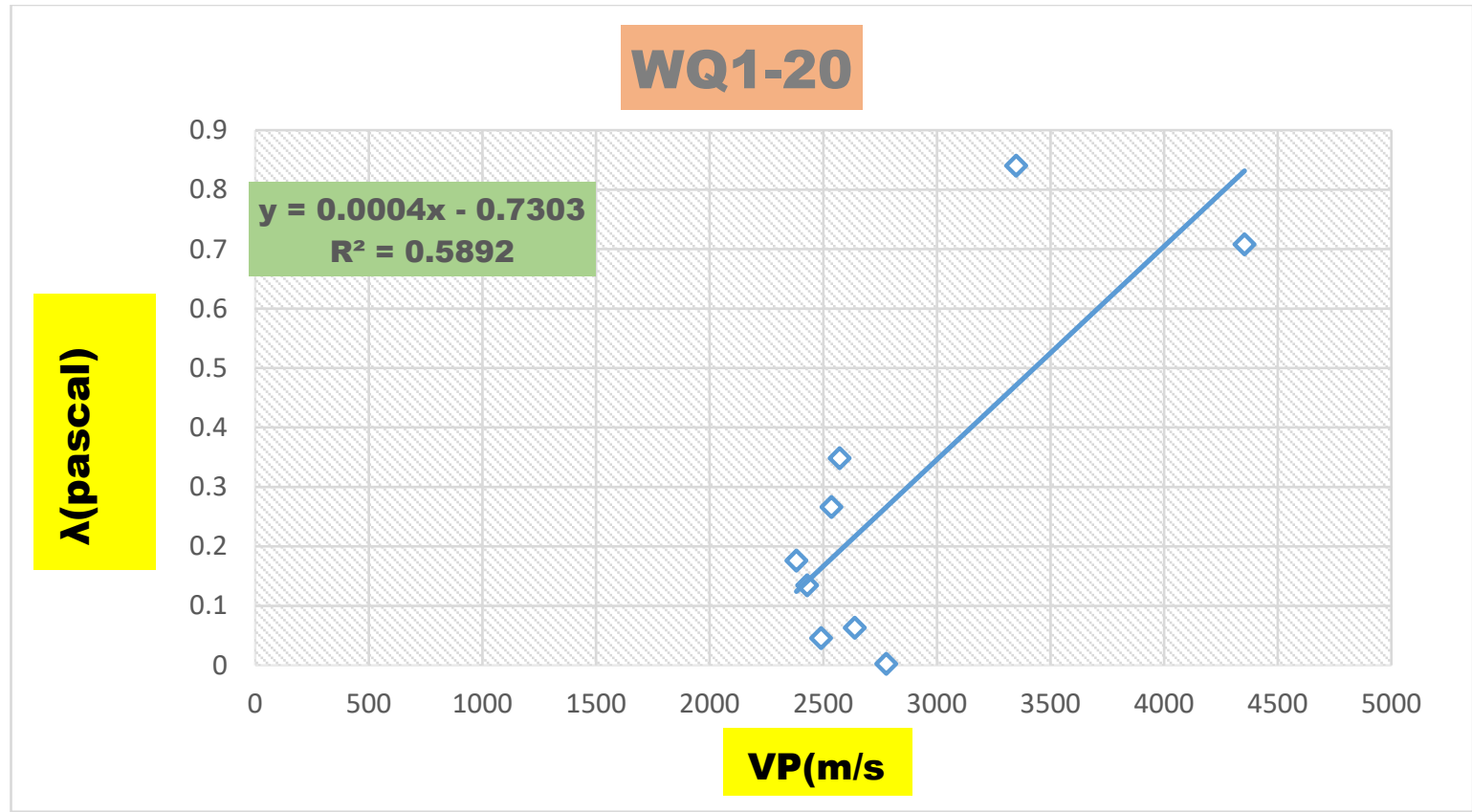

Figure 15-The relationship between Vp and $\lambda$ for the core plugs

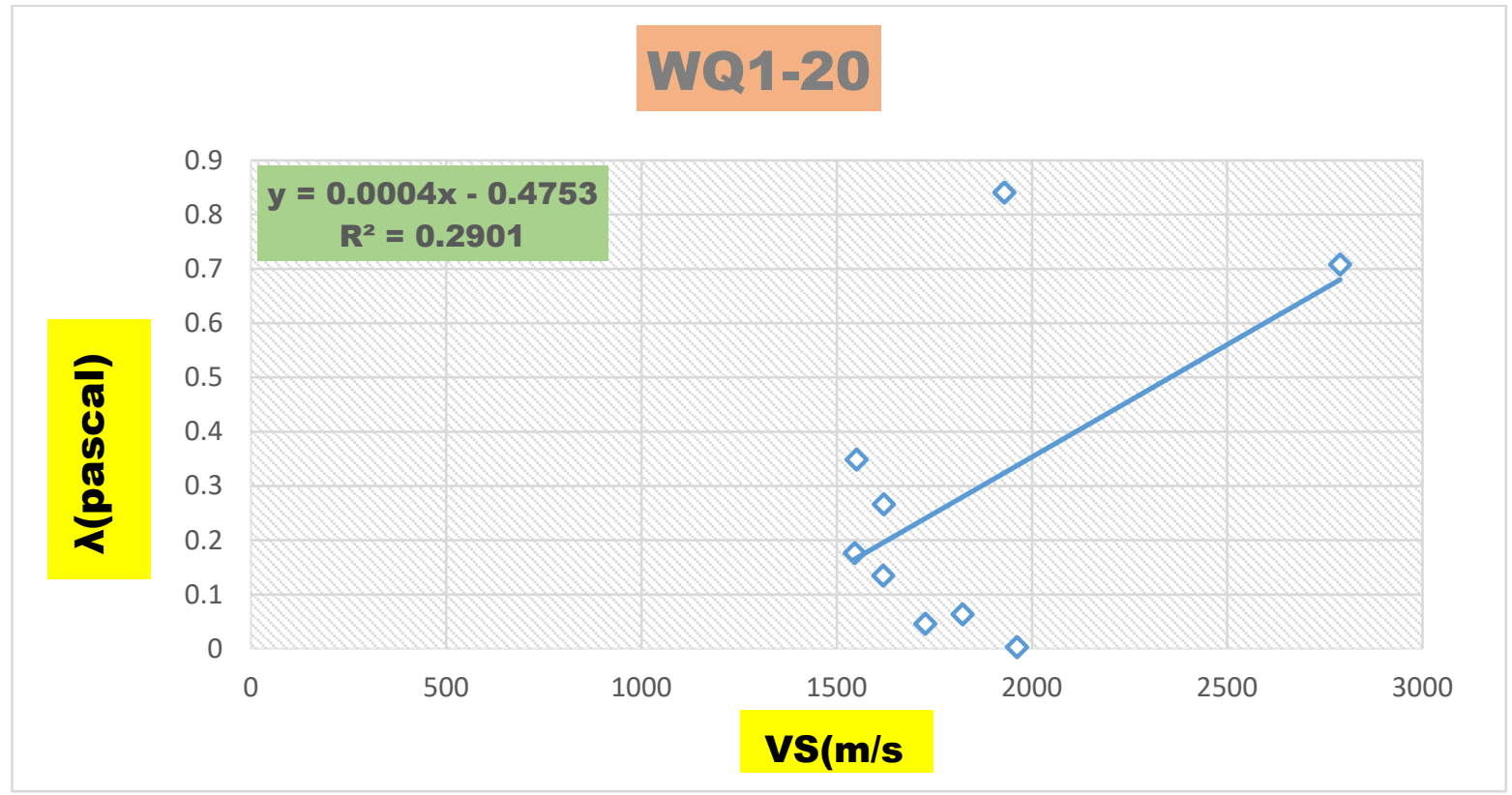

Figure 16-The relation between Vs and Lame's constants (K) for the core plugs

\section{PRESENT WORK APPLICATIONS}

The estimated relationship between P-and S-wave velocities from the core plugs in the lab was used to find S-wave velocity for the log with Vp log and plotted with Vs that is found from the correlations (Pickett, 1963; Carroll, 1969; and Al-Kattan, 2015) as shown in Figure 17. 


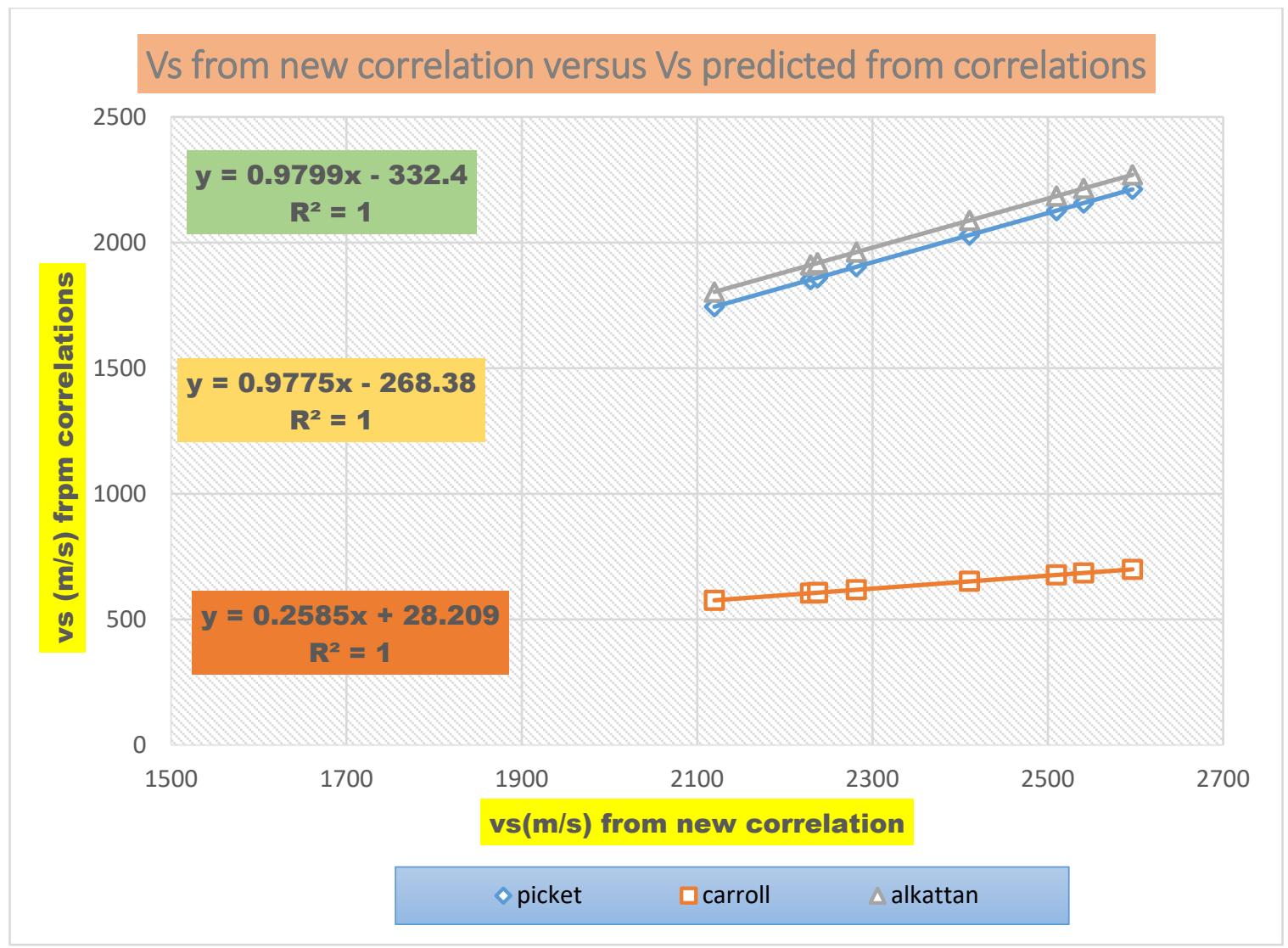

Figure 17:the Vs predicted from new correlation versus Vs from the correlations

The above figure shows a good relationship between the correlations and the new correlation.

\section{CONCLUSIONS}

This study aims to find the elastic properties for Mishrif formation in the West Qurna-1 oil field by determining the relationships between rock properties and $\mathrm{P}$-and $\mathrm{S}$-wave velocities from the experimental work.

The results showed a linear relationship between $\mathrm{P}$ and $\mathrm{S}$-wave velocities with dynamic elastic properties of carbonate rock where the values of determination coefficient $\left(\mathrm{R}^{2)}\right.$ are different for each value.

With $\mathrm{R}^{2}$ greater than 0.9 between $\mathrm{P}$-wave velocities and parameters such as density and lame's constant, bulk modulus, density, and lame's constant may be best linked to the Pwave velocity. Young's modulus is related with the $\mathrm{P}$-wave velocity with $\mathrm{R}^{2}$ equal to 0.97 while with an S-wave velocity equal to 0.92 .

The relation between $\mathrm{Vp} / \mathrm{Vs}$ ratio with Poisson's ratio showed a good $\mathrm{R}^{2}$ with a value of 0.97 . 
From the current study, empirical equations were obtained that revealed the elastic properties of the carbonate rocks that can be determined by the ultrasonic wave velocities.

\section{References}

1-Liu, Y., Z. Chen, and K. Hu (2012), Shear velocity prediction and its rock mechanic implications. In: Conf. GeoConvention 2012: Vision, 14-18 May 2012, Calgary, Canada, $5 \mathrm{pp}$.

2. Chawre, B. 2018. Correlations between ultrasonic pulse wave velocities and rock properties of quartz-mica schist, Journal of Rock Mechanics and Geotechnical Engineering, 10: 594-602.

3. Yasar, E. and Erdogan, Y. 2004. Correlating sound velocity with the density, compressive strength, and Young's modulus of carbonate rocks, International Journal of Rock Mechanics \& Mining Sciences, 41(5): 871-875.

4. Soroush H, Qutob H. 2011. Evaluation of rock properties using ultrasonic pulse technique and correlating static to dynamic elastic constants. In: Proceedings of the 2nd South Asian Geoscience Conference and Exhibition (GEOIndia2011). New Delhi, India;

4. Soroush H, Qutob H. 2011. Evaluation of rock properties using ultrasonic pulse technique and correlating static to dynamic elastic constants. In: Proceedings of the 2nd South Asian Geoscience Conference and Exhibition (GEOIndia2011). New Delhi, India;

5. Musa, M., Hasan, A. and Khairul A. 2010. Determination of Seismic Wave of Consolidated Granite Rock in Penang Island: Ultrasonic Testing Method Vs Seismic Refraction Method, international journal of Geotechnical and Geological Engineering, 4(10): 494- 496.

6. Kłeczek, I. 2016. The study of the elastic properties of carbonate rocks on a base of laboratory and field measurement, Acta Montanistica Slovaca, 21(1): 76-83.

7. Maev, R.G. 2008. Acoustic Microscopy: Fundamentals and Applications, John Wiley \& Sons, Betz-Druck GmbH, Weinheim, Germany.

8. Vasconcelos, G., Lourenço, P.B., Alves, C.A.S. and Pamplona, J. 2008. "Ultrasonic evaluation of the physical and mechanical properties of granites", Ultrasonics, 48(5): 453466.

9. Lotfi, H., Faiz, B., Moudden, A., Izbaim, D., Menou, A., and Maze, G. 2010. "Characterization of mortars with ultrasonic transducer", MJ Condensed Matter, 12(2): 131-133. 
10. Shariati, M., Ramli-Sulong, N.H., KH, M.M.A., Shafigh, P. and Sinaei, H. 2011. "Assessing the strength of reinforced concrete structures through ultrasonic pulse velocity and Schmidt rebound hammer tests", Sci. Res. Essays, 6(1): 213-220.

11. Chen, X., Schmitt, D.R., Kessler, J.A., Evans, J. and Kofman, R. 2015. Empirical relations between ultrasonic P-wave velocity, porosity, and Uniaxial Compressive Strength, CSEG Rec., 40(5): 24-29.

12. Fener M. 2011. The effect of rock sample dimension on the P-wave velocity. Journal of Nondestructive Evaluation; 30(2): 99-105.

13. Kurtulus, C., Bozkurt, A. and Endes, H. 2012. "Physical and mechanical properties of serpentinized ultrabasic rocks in NW Turkey", Pure and Applied Geophysics, 169(7): 1205-1215.

14. Khandelwal M. 2013. Correlating P-wave velocity with the physico-mechanical properties of different rocks. Pure and Applied Geophysics 2013; 170(4): 507-514.

15. Wang F, Bian H, Yu J. and Zhang Y. 2016. Correlation of dynamic and static parameters of rock.Electronic Journal of Geotechnical Engineering; 21(4):1551- 1560.

16. Lai, G.T., Rafek, A.G., Serasa, A.S., Hussin, A. and Ern, L.K. 2016. "Use of ultrasonic velocity travel time to estimate uniaxial compressive strength of granite and schist in Malaysia”, Ssains Malays., 45(2): 185-193.

17. Nourani MH, Moghadder TM. and Safari M. 2017. Classification and assessment of rock mass parameters in Choghart iron mine using P-wave velocity. Journal of Rock Mechanics and Geotechnical Engineering; 9(2): 318-328. 